Shear capacity of steel fibre reinforced concrete coupling beams using conventional reinforcements

Peer-reviewed author version

CAI, Gaochuang; Zhao, Jun; DEGEE, Herve \& VANDOREN, Bram (2016) Shear capacity of steel fibre reinforced concrete coupling beams using conventional reinforcements. In: Engineering structures, 128, p. 428-440.

DOI: $10.1016 /$ j.engstruct.2016.09.056

Handle: http://hdl.handle.net/1942/22585 


\title{
Shear capacity of steel fibre reinforced concrete coupling beams using conventional reinforcements
}

Gaochuang Cai ${ }^{1}$, Jun Zhao*2, Herve Degee ${ }^{1}$, Bram Vandoren ${ }^{1}$

1 CERG, Faculty of Engineering Technology, Hasselt University, Hasselt, Belgium

2 School of Mechanics and Engineering Science, Zhengzhou University, Zhengzhou, China

* Corresponding author: Jun Zhao, Professor, Ph.D.

School of Mechanics and Engineering science, Zhengzhou University, Zhengzhou, China

No.100 Kexue Avenue, Zhengzhou, Henan, China

Postcode: 450001

Email: caiyang2010@126.com

Tel: +32-11-292160

\begin{abstract}
The seismic performance of coupled shear wall systems is governed by the shear resistance of their coupling beams. Steel fibre reinforced concrete (SFRC) is widely applied in coupling beams for its positive contribution to their ductility. This study deals with the seismic behaviour of SFRC coupling beams using conventional reinforcements and develops a simplified model that applies the Mohr-coulomb failure criterion to predict the seismic shear strength of SFRC coupling beams. Variables studied include concrete compressive strength, fibre volume fraction and span- to-depth ratio. Results show that steel fibres improve the shear strength, deformation and energy dissipation capacity of the SFRC coupling beams. When fibre volume fraction is greater than $2.5 \%$ or span-to-depth ratio excesses 2.5 , SFRC coupling beams present an excellent seismic performance and avoid effectively brittle shear failure. Using the Mohr-Coulomb failure criterion, a simplified shear model was proposed for SFRC coupling beams and presents a good accuracy and reliability. Furthermore, taking into account the negative effect of span-to-depth ratio, the proposed shear model was modified further. The comparative results demonstrated that the new shear model presents a more reasonable assessment accuracy and higher reliability.
\end{abstract}

Keywords: Shear strength; Steel fibre reinforce concrete; Seismic assessment; Coupling beam; Mohr-coulomb failure criterion; 


\section{Introduction}

Reinforced concrete (RC) walls are widely applied in medium-rise RC building systems in order to resist effectively seismic effects due to their good stiffness properties and lateral resisting capacity. The presence of openings or other function requirements (e.g. windows and doors) in shear wall systems, however, results in the emergences of some special walls or connection elements such as slender wall and coupling beam (CB). They require structural designers to concern carefully for guarantying the seismic resistance of whole coupled RC (shear) wall system. Fig. 1 shows some simple schematics of the system including a RC wall, a coupled RC wall, CBs as well as their seismic response and design. During an earthquake, the primary purpose of CBs is to realize effectively shear transferring between two single RC shear walls. A well-designed coupled $\mathrm{RC}$ shear wall system generally presents a higher overall strength, better stiffness properties and energy dissipation capacity than the simple superposition of the individual walls [1]. In addition, coupling beams in coupled RC wall system are usually subjected to a higher cyclic shear reversal and a larger inelastic excursion [2] than the RC walls during an earthquake. Therefore, brittle shear failure, shear strength and deformation capacity are considered as the most critical concerns of RC coupling beams.

On the other hand, according to previous experimental investigations of coupling beams in 1970s (e.g. Luisoni et al.[3], Paulay et al.[4,5]) and an investigation report from American Iron and Steel Institute [6] focused on RC coupling beams with conventional horizontal distributed reinforcements, diagonally distributed reinforcement has been developed and used firstly for $\mathrm{RC}$ coupling beams (see Fig.2). Subsequent experimental study [7] has verified further that this kind of RC coupling beams was able to resist higher shear loads and larger deformation as well as to dissipate more earthquake energy comparing with the ones using conventional reinforcements. As shown in Fig.2, the utilization of diagonally reinforcements, however, brings a new problem of construction inconvenience due to the congestion of reinforcements in RC coupling beams. This disadvantage will be aggravated when coupling beams have a relative high depth-width ratio. In order to solve the problem, Chaallal et al. [8] experimentally investigated some high performance concrete coupling beams using steel fibres to replace partially the reinforcements of RC coupling beams. Their results illustrated that these fibre concrete coupling beams presented an equally distributed force situation and a higher energy dissipation capacity when compared with conventional RC coupling beams. This was attributed to the fact that SFRC beam can resist a higher shear deformation and provide a better cracking resistance capacity than normal RC ones, which is same as the one reported by previous studies [e.g. 9]. Lequensne et al. [10] also reported that high performance fibre reinforced concrete (FRC) can reduce the required area of diagonal reinforcements by $70 \%$ relative to a code-compliant design. Besides, Canbolat et al. [1] also illustrated that the use of high-performance fibre reinforced cement composites (HPFRCC) could 
be an alternative design proposal for $\mathrm{RC}$ coupling beams of the shear wall systems without using diagonal reinforcements. They explained that HPFRCC exhibits a tension strain hardening behaviour even though it still has a number of cracking and concrete crunching. It implies that fibre reinforced concrete could be used to reduce the dependency of heavily diagonal reinforcing in coupling beams while maintaining similar strength and ductility to well-detailed diagonally reinforced ones [1].

Besides, comparing with normal RC coupling beams, HPFRCC coupling beams can exhibit a higher deformation capacity with more uniform crack distribution and stable strength degradation [11]. Zhang et al. [12] also experimentally verified that the ductility and energy dissipation capacity of SFRC coupling beams using moderate steel fibres both were enhanced in about $20 \%$ when compared with the ones of normal RC coupling beams. However, the experimental investigation focusing on the seismic behaviour of SFRC coupling beam is still very limited. In addition, as one of the most important seismic design indexes of RC members, the shear strength of RC coupling beams is currently being concerned by structural research community. The work conducted by Parra-Montesinos [11] demonstrated that the HPFRCC increases effectively the shear strength and confinement of RC coupling beams subjected to shear reversals. However, as regards to SFRC coupling beams, there is not universally-accepted method to predict their seismic shear strength.

The primary purpose of the current study is to develop a practical design model for predicting the shear strength of SFRC coupling beams with conventional reinforcements using some relevant theories and the deformation mechanism of SFRC coupling beams under high shear reversals. Meanwhile, the seismic behaviour of SFRC coupling beams will be experimentally investigated and synoptically discussed. Through comparing experimental results of the SFRC coupling beams and the test data obtained from literature review, existing and proposed models to predict the shear strength of SFRC coupling beam will be examined and discussed.

\section{Existing evaluation models for evaluating the shear strength of SFRC coupling beams}

As described previously, while extensive studies have focused on the shear behaviour of RC coupling beams, a few shear design methods have been proposed for them specifically for SFRC coupling beams. Aktan and Bertero [13] and Aristizabal-Ochoa [14] reported that conventionally reinforced concrete coupling beams (CCBs) still exhibit a satisfactory performance when their nominal gross section shear stress are below to $0.25 f_{c}{ }^{0.5}$ (in $\mathrm{MPa}$ ), if they failed in a flexure-dominate mode. Besides, ACI 318 code [15] recommended that the RC coupling beams with a span/depth ratio $\left(l_{n} / d\right)$ of less than 4.0 could be designed into a diagonally reinforced concrete coupling beams (DRCBs). On the other hand, the code also requires that the coupling beams with $l_{n} / d$ of less than 2.0 and the ones with a sectional stress exceeding $0.33 f_{c}{ }^{0.5}$ (in MPa) on gross sectional area must be designed to use diagonally reinforcements. Moreover, the diagonal 
elements must have a width outside dimension exceeding half of beam width and a depth of 0.2 times beam width, referring to Section 21.7.7.4 (a) in ACI 318 [15]. For the coupling beams with $l_{n} / d$ of greater than 4 , the code suggested the beams should satisfy the requirements in Section 21.5 which means that they should be designed as flexural members in term of special moment frames.

Lequesne and Wight [16] have proposed a calculation method to predict the shear strength of FRC coupling beams which consists of three shear contributions from conventional transverse reinforcements, diagonal reinforcements and fibre reinforce concrete respectively. The design equation is given by,

$$
V=V_{c f}+V_{s d}+V_{s}=0.4 \sqrt{f_{c}^{\prime}} b_{w} d+\left(2 A_{v d} f_{y} \sin \alpha\right)+\frac{A_{v} f_{y t} d}{S}
$$

where, $V_{s d}$ is taken as zero for the SFRC coupling beams only having conventional reinforcements.

Zhang et al. [12] have reported that the addition of moderate volume of steel fibres not only can enhance the shear strength of RC coupling beams, but also can improve the spalling resistance of cover concrete, as well as the concrete crushing or the damage at shear-compressive zones. This is benefited to ultimate failure modes of RC coupling beams, that is to realize the favorable change from shear-dominant failure to flexure-dominant failure models. Meanwhile, according to the research on SFRC coupling beams with low span-depth ratio $\left(l_{n} / d \leq 2.5\right)$ and using conventional reinforcements, Zhang et al. [12] have proposed a shear strength model for these SFRC coupling beams on the basis of Chinese design code [17], which can be expressed in the form of,

$$
V=V_{c f}+V_{s}=0.8\left(1+0.7 \lambda_{f}\right) f_{t} b h_{0}+0.45 \frac{A_{v} f_{y} h_{0}}{S}
$$

where, $\lambda_{f}$ is a characteristic value of steel fibre calculated as $\rho_{f} l_{f} / d_{f} . f_{t}$ is the tensile strength of original concrete obtained from tension test referring to Chinese test standard [17]. $\rho_{f}$ is fibre volume fraction, and $l_{f} / d_{f}$ is the aspect ratio of steel fibre. $h_{o}$ is the effective sectional depth of coupling beam which is taken as the distance from the center of tensile longitudinal reinforcements to compressive concrete edge.

\section{Proposed formula for evaluating the shear strength of SFRC coupling beams}

\subsection{Failure mechanism}

$\mathrm{RC}$ coupling beams subjected to seismic loads usually present a similar deformation development and some primary damage characteristics when compared with RC columns. To clearly understand the shear transferring and failure behaviour of SFRC coupling beams, the deformation and failure mechanism of normal RC coupling beams are briefly reviewed here.

When subjected to a low transversal reversed cyclic load, RC coupling beams can deform elastically or freely as the RC support elements under seismic loads. In theory, the enhancement action of steel fibres to concrete is not obvious at this moment because the steel fibres just are considered as aggregates in a non-cracked concrete. Once the first flexural crack was observed, 
however, the elastic deformation of RC coupling beam stops and steel fibres start to work at the cracked section and the beam begins to resist flexural deformation. Since the emergence of the first shear crack, a well-designed RC coupling beam usually presents stable flexural and shear cracking development. The process accompanies generally with a further degradation of stiffness and spalling of concrete cover until the beam achieves its maximum shear resistance capacity. Subsequently, certain longitudinal steel rebar starts to yield and the shear resistance of RC coupling beam reduces due to the degradation of dowel action of longitudinal steel or the decline of interlock action of coarse aggregates in concrete etc. Finally, RC coupling beam fails due to the loss of shear resistance caused by the yielding of more reinforcement rebars or a crushing in core concrete.

The ultimate failure mode of RC coupling beam can be divided into three types, i.e., flexure failure, flexure-shear failure and shear failure modes respectively. For the RC coupling beams with flexure-dominant failure mode, flexure cracks usually can obtain a sufficient development without obvious diagonal shear cracks. This failure is usually caused by a lateral moving of coupling beam at its main flexural cracked section which normally at the ends of coupling beams. Flexural-slip failure mode was considered as one of classic flexure-dominant failure modes caused usually by the buckling action of some longitudinal reinforcement bars at main cracked section [18]. With regard to RC coupling beams failed in shear mode, however, these beams usually show completely developed shear cracks in their hinge region before longitudinal steel rebars achieve their yielding level, even though the first crack is still a flexural type. Subsequently, after some shear loading cycles, some major 45-degree and large-width major shear cracks begins to occur and results in a rapid degradation in shear strength until final failure, regardless of the yielding of longitudinal reinforcements. On the other hand, for RC coupling beams with flexure-shear dominant failure mode, longitudinal reinforcements usually achieve their yielding status after a stable and continuous cracking development. The beams also can present main diagonal shear cracks once their residual shear strengths at certain displacement are lower than their flexural resistance capacities. In these cases, the shear strength of this type of coupling beams usually deteriorates when certain transverse shear reinforcement fractures or starts to yield.

\subsection{Calculation formula of shear strength for SFRC coupling beams}

The Mohr-Coulomb theory is a widely-used mathematical model that describes the response of brittle materials such as concrete. Most of classical engineering materials somehow follow this rule in at least a portion of their shear failure envelope [19]. As shown in Fig.3, the Mohr-Coulomb failure criterion represents a series of linear failure envelope curves (or can be called as strength curves) in a principal stress plane (see Plane $\boldsymbol{B}$ ) that can be obtained from a relationship between the shear stress $(\tau)$ and subjected normal stress $(\sigma)$, as shown in Eq. (3). It should be noted that the compression direction is assumed to be positive in the following discussions.

$$
\tau=\sigma \tan \theta+c
$$


In this equation, $\tau$ is the internal shear stress, $\sigma$ is normal stress, and $\boldsymbol{c}$ is the intercept of the failure envelope in the shear stress axis, which is often called cohesion; $\boldsymbol{\theta}$ represents the internal angle of friction which is computed as the slope of failure envelope curve in this figure.

According to previous descriptions, it is very important to develop a shear strength equation with a proper physical meaning for SFRC coupling beams taking into account main shear transfer mechanisms of coupling beam with shear-dominant failure mode and the effects of key structural factors. Fig. 4 shows the various shear transfer mechanisms of SFRC coupling beams using stirrups and conventional reinforcements. Referring to above described analyses regarding the deformation and failure mechanisms of normal RC coupling beams under reversed shear cyclic loads, some basic assumptions are made: (1) The diagonal plane has an inclination of 45-degree with the longitudinal direction of beam which has been experimentally verified by previous studies and analyses [e.g. 1, 20]; (2) The failure of diagonal plane complies with the Mohr Coulomb failure criterion which is similar to RC columns under seismic loads [21]; (3) With regards to the internal compression strut effectiveness, Kowalsky and Priestley [22] considered that a typical value of compression zone range from 0.25 to 0.35 times of overall depth of RC columns under seismic loads. However, for SFRC coupling beams with conventional reinforcements, considering without strong axial compressive action because of the absence of external axial loads but having the enhancement effect of steel fibres to concrete at cracked section, the compression zone is taken as $10 \%$ of beam depth in SFRC coupling beams; (4) Similar to RC columns subjected to seismic loads, the tensile and compressive longitudinal reinforcing bars in coupling beams can balance themselves internally [21].

On the basis of the above assumptions and considering with the equilibrium of all forces depicted in Fig.4, the balance equations in the directions $\boldsymbol{X}$ and $\boldsymbol{Y}$ are obtained, as follows,

$$
\begin{aligned}
& \sum Y=V_{u}+\sigma_{c f} \frac{0.9 d b}{\sin \theta} \cos \theta-\tau_{c f} \frac{0.9 d b}{\sin \theta} \sin \theta-\sum V_{s i}-V_{c}=0 \\
& \sum X=\left(\sum T_{i}-C\right)-F_{c}-\sigma_{c f} \frac{0.9 d b}{\sin \theta} \sin \theta-\tau_{c f} \frac{0.9 d b}{\sin \theta} \cos \theta=0
\end{aligned}
$$

Meanwhile, using the assumption of the internal compression strut effect described above, the ultimate compressive resistance force of concrete $F_{c}$ in compression zone is expressed as,

$$
F_{c}=0.1 f_{c r c}^{\prime} b d
$$

where, $f_{\text {cfrc }}$ 'is fibre concrete compressive strength.

Therefore, according to the assumptions (1) and (4), the equilibrium equations in the directions of $\boldsymbol{X}$ and $\boldsymbol{Y}$ axis are expressed in the following forms of,

$$
\sum Y=V_{u}+0.9 d b \sigma_{c f}-0.9 d b \tau_{c f}-V_{s}-V_{c}=0
$$




$$
\sum X=-F_{c}-0.9 d b \sigma_{c f}-0.9 d b \tau_{c f}=0
$$

In the two equations, by introducing two calculation factors $\boldsymbol{A}$ and $\boldsymbol{B}$, as well as denoting the compression-to-tension strengths ratio of steel fibre concrete as $\gamma$ and by referring to the simplifying method of the Mohr-Coulomb failure criterion in conventional concrete proposed by Architecture Institute Japan (AIJ) [21], the Mohr-Coulomb failure criterion for steel fibre concrete is presented as,

$$
\tau_{c f}=A f_{c r c}^{\prime}+B \sigma_{c f}
$$

where, the factors $\boldsymbol{A}$ and $\boldsymbol{B}$ are taken as $1 / 2 \sqrt{\gamma}$ and $(\gamma-1) / 2 \sqrt{\gamma}$, respectively.

Therefore, based on Eqs. (7)-(9), the shear strength of SFRC coupling beams is computed as,

$$
V_{u}=V_{s}+V_{c}+\frac{1.8 A-0.1 B+0.1}{B+1.0} f_{c f r c}^{\prime} b d
$$

In the equation, the shear forces of the 45-degree truss mechanism $V_{s}$ and shear contribution of concrete $\boldsymbol{V}_{\boldsymbol{c}}$ are obtained referring to the model proposed by ASCE-ACI committee 426 [23] (no axial load), shown as the following two equations,

$$
\begin{aligned}
& V_{s}=\frac{A_{v} f_{y t} 0.8 d}{S} \\
& V_{c}=0.29 \sqrt{f_{c f r c}^{\prime}} 0.8 b d
\end{aligned}
$$

As a consequence, the shear strength of SFRC coupling beams is given by,

$$
V_{u}=\frac{A_{v} f_{y t} 0.8 d}{S}+0.29 \sqrt{f_{c f r c}^{\prime}} 0.8 b d+\frac{1.8 A-0.1 B+0.1}{B+1.0} f_{c f r c}^{\prime} b d
$$

Referring to the various primary shear contributions of RC columns in Priestley et al. model [24], the last shear components in Eq. (13) can be considered as a comprehensive influence of steel fibres on the shear transfer mechanism of coupling beam located at diagonal cracked section. On the other hand, it was well known that the value of $\gamma$ ranges from 10 to 16 for conventional concrete [25] which has been simply considered as 10 in circular concrete columns reported by first author of this paper [21]. However, due to the addition of steel fibres, the compressive and tensile strengths of steel fibre concrete both change simultaneously. Moreover, the increasing levels of the two strengths of steel fibre concretes are different and depend nonlinearly on each other. This indicates the using of a constant ratio $\gamma$ that is same as the one in normal concrete is not appropriate in steel fibre concretes. $\mathrm{Xu}$ and Shi [26] evaluated the relationship of compressive strength, splitting tensile strength and flexural strength of concretes using various fibres as well as proposed an empirical model for predicting the splitting tensile strength of the concretes using their compressive strengths. However, their database only included a few specimens using straight steel 
fibres. In order to investigate the relationship between the ratio $\gamma$ and steel fibres volume fraction, a basic experimental investigation focusing on the mechanical properties of straight steel fibre concretes is performed in this study. The test program used some usually-used steel fibre concretes with a compressive strength ranging from $30 \mathrm{MP}$ to $80 \mathrm{MPa}$. The volume fractions of steel fibre (straight) in the concretes are less than $3.0 \%$ which has been recommended in the most of practical guidelines or research [27]. In this study, the tensile strengths of all concretes were obtained by a series of splitting tensile tests using three concrete cube specimens for each strength level, while their compressive strengths were measured through three cube concrete specimens according to Chinese test standard [28].

Figs.5 (a) and (b) shown the relationship model proposed by $\mathrm{Xu}$ and Shi [26] over-evaluates the test results of straight steel fibre concrete, and the amplitude of this over-evaluation decreases with fibre volume fraction. Meanwhile, as shown in Fig.5 (c), according to the research and the collected data from previous study [12] using straight steel fibre, the ratio $(\gamma)$ of compressive strength to tensile strength of steel fibre concrete degrades linearly with fibre volume fraction ranging from $0 \%$ to $3 \%$. In consequence, to simply simulate this trend, the ratio $\gamma$ is calculated as,

$$
\gamma=14.5-1.78 \rho_{f} \quad\left(\rho_{f} \text { in } \%\right)
$$

Based on the equation, although the values of factors $\boldsymbol{A}$ and $\boldsymbol{B}$ can be obtained, the shear calculation equation of SFRC coupling beams using the two factors is still too complex. For this, the direct relationship between fibre volume fraction and these two factors was studied as shown in Fig.6. Considering the common application ratio of steel fibre in practical concrete elements varies from $0 \%$ to 3\% [27], the simplified models of $\boldsymbol{A}$ and $\boldsymbol{B}$ are expressed respectively as,

$$
\begin{aligned}
& A=0.13+\rho_{f} \\
& B=1.78-14 \rho_{f}
\end{aligned}
$$

Therefore, based on above analyses and calculation, the shear strength of FRC coupling beams, is presented as,

$$
\begin{aligned}
& V_{u}=V_{s}+V_{c}+\frac{0.156+3.2 \rho_{f}}{2.78-14 \rho_{f}} f_{c f r c}^{\prime} b d \\
& \lambda=\frac{0.156+3.2 \rho_{f}}{2.78-14 \rho_{f}}
\end{aligned}
$$

In Eq.(16), an enhancing factor $\lambda$ is defined to consider a comprehensive improvement of steel fibre to RC coupling beams and predominantly depends on fibre volume fraction, as shown in Eq. (17). When fibre volume fraction increases up to $3.0 \%$ of concrete, this enhancing coefficient linearly increases, as shown in Fig.7. Using this simplified relationship, the shear strength of SFRC 
coupling beams is expressed further as Eq.(18). In summary, this proposed shear strength model uses a widely-accepted failure criterion and presents mathematical simplicity, clear physical meaning of materials and considers the effects of some main structural parameters on shear behaviour of RC coupling beams.

$$
V_{C B}=0.29 \sqrt{f_{c f r c}^{\prime}} 0.8 b d+\frac{A_{v} f_{y t} 0.8 d}{S}+\left(0.055+1.7 \rho_{f}\right) f_{c f r c}^{\prime} b d
$$

\section{Experimental investigation}

\subsection{Experimental program}

In order to verify experimentally the proposed shear strength model, 17 SFRC coupling beams with conventional reinforcements and straight steel fibre have been tested under lateral reverse shear cyclic load. The main variables investigated are the compressive strength of fibre reinforced concrete, span-to-depth ratio and fibre volume fraction.

Each of these specimens consisted of an approximately $1 / 3$-scale coupling beam with an overall depth of $400 \mathrm{~mm}$ and two structural RC walls with relative high stiffness and concrete strength, as shown in Fig.8. The span-to-depth ratios of the specimens ranged from 1.0 to 3.5 and most of them were designed as 2.0 to ensure their shear-dominant failure. The details of all specimens and the properties of all used materials are listed in Table.1. Using corresponding Chinese test standards, the compressive strength and splitting tensile of steel fibre reinforced concretes as well as the main mechanical properties of reinforcements were obtained by testing three specimens at each strength level respectively. The compressive strengths of the concretes range from $40 \mathrm{MPa}$ to $80 \mathrm{MPa}$. The fibre volume fractions are between $0 \%$ and $2.5 \%$ of concrete. The steel fibre used in this study is straight type which has an aspect ratio of 42 and a yielding strength of 380MPa. The details of test setup and loading method are shown in Fig.9. To evaluate the seismic response of these SFRC coupling beams, all specimens have been designed according to Chinese standard of CECS13-2009 [28] and Chinese National testing guideline JGJ101-1996 [29]. Uniformly distributed longitudinal and transverse reinforcements were arranged to resist flexural and shear deformation of these coupling beams.

As shown in Fig.9, each specimen was placed and rotated into the test setup system by connecting the upper stiff $\mathrm{RC}$ shear wall to strong reaction $\mathrm{RC}$ walls $(\boldsymbol{D})$, and fixed to strong floor (Strong steel beam, $\boldsymbol{C}$ ) through the bottom RC shear wall. A quasi-static load was performed to the upper stiff RC shear wall through a horizontal hydraulic actuator $(A)$ in the term of passing through the mid-span of coupling beams to induce an anti-symmetrical moment pattern to these coupling beams. The actuator was connected to the upper RC structural wall via a strong L-type steel loading frame $(\boldsymbol{B})$ consisting of two high stiffness steel I-section beams. To connect the upper RC wall and the steel frame, four steel triangular-steel connect plates were fixed to the upper shear wall through 
four pre-set steel bars $(\boldsymbol{I})$. All steel connection plates and rebars have a high stiffness to ensure the stability and safety of the whole loading system during testing.

A cyclic loading used in the vertical direction of beams was divided clearly into two phases as shown in Fig.10. To observe and collect detailed information of cracking development of the specimens at early stage, a load-control type loading (single cyclic for each level) was applied firstly until certain longitudinal reinforcement achieved its yielding level or when the envelope curve of the load-displacement of this specimen exhibits an obvious yielding point. At this moment, the specimen was considered to reach its yielding displacement $(\Delta)$ in this study. Subsequently, to simulate the demands and impacts of earthquake action, some displacement-control loading cycles ( 2 cycles for each level) with certain displacement level were applied to each specimen, starting from 1.0 time yielding displacement $(\Delta)$ (i.e. 1.04, 2.04,3.04, etc.). During the testing, the cracking development, failure and detailed deformation and force of the specimens were recorded and monitored carefully. For the security, test will be finished if the lateral resistance force of specimen reduces to $85 \%$ of its maximum measured value. The basic variables and main test results of all coupling beams are listed in Table.1.

\subsection{Main experimental results}

Since main experimental deformation observations and results are very helpful to understand clearly the shear behaviour of SFRC coupling beam, the main experimental results of all tested coupling beams are synoptically summarized in this section, focusing on: failure modes, stiffnesses development, shear strength and behaviour etc.

\subsubsection{Damage situation and failure modes of SFRC coupling beams}

As listed in Table.1, classical diagonal tension and compression failures were observed in most of specimens together with diagonal shear damage, expect for the specimens with a span-to-depth of greater than 2.0 or the ones having a high fibre volume fraction (e.g. $>2.5 \%$ ). A similar effect of span-to-depth on the cracking pattern of RC coupling beams has been reported by other researchers [30]. The results of the SFRC coupling beams using $2.5 \%$ of steel fibre also experimentally verified the superior cracking resistance of steel fibre in RC coupling beams as well as a reasonable and uniform shear transfer mechanism at the cracked sections of the specimens. Regarding the SFRC specimens with shear-dominant failure mode, some flexural cracks were usually observed at the hinge regions of the beams $\left(0.5 \sim 1.0 l_{n}\right.$ from the ends of beam, similar to the one in RC columns) which presents their resistance to flexure deformations. Subsequently, some shear cracks were expectedly observed in the specimens after their flexure cracks expanded further and widened caused by larger lateral loads. From this moment, the stiffness of the SFRC beams generally started to degrade and presented an obvious yielding point in their envelop curves of load-deformation. When the shear resistance force of the shear failure coupling beams are reduced to $75-85 \%$ of their 
ultimate resistance values, main diagonal (45 degree X-type) cracks were confirmed in the specimens and the concrete cover usually started to spall as well. With these diagonal cracks widen further, some steel fibres located at diagonal cracked section started to be pulled out or fractured as well as the shear resistance forces of coupling beams reduced sharply. The damage of diagonal shear-tension or compression appeared at 45-degree cracked section of the coupling beams, before their shear resistance forces degraded to $85 \%$ of their corresponding ultimate levels.

Regarding the SFRC coupling beams with different compressive strength fibre concrete, the specimens shown higher cracking resistance loads and ultimate load-carrying capacities as their compressive strengths increased. The specimens with low compressive strength usually failed as a shear-compression mode due to the concretes located at diagonal section tip were crushed usually at the late stage of loading. On the other hand, when SFRC coupling beams use a higher strength fibre concrete, the beams show more and wider diagonal cracks at late stage of loading, replacing of the crushing of concrete. This can be explained by the fact that high strength fibre concrete in diagonal margin can resist more cycles of reverse tension compression action, which usually results in a shear tension failure mode. When steel fibre concrete has higher compressive strength such as $80 \mathrm{MPa}$ used in this study, however, the high compressive resistance directly resulted in the fast development and extending of 45-degree main diagonal cracks at early stage. This means that this kind of coupling beam will present a classic shear-dominant failure possibly.

In addition in the SFRC coupling beams with different span-to-depth ratio $\left(l_{n} / d\right)$, all specimens show a similar cracking-resistance capacity of about $30 \mathrm{kN}$. As $l_{n} / d$ ratio increases, the failure modes of SFRC coupling beams have been changed from brittle shear to flexure-shear/flexure failure mode. When the ratios of $l_{n} / d$ were small levels such as 1.0 and 1.5, large-width cracks were observed and no obvious lateral moving was confirmed in these coupling beams. On the other hand, when the $l_{n} / d$ ratios ranged from 2.0 to 3.0, some classical flexure-shear failures were confirmed accompanying with two X-type main diagonal cracks at two ends (hinge zone) of these beams. The damage of the core parts of the two X-type cracking zones increases with $l_{n} / d$ ratios. When $l_{n} / d$ increases up to 3.5 , however, the failure mode of coupling beam completely switched into flexure failure mode which was mainly attributed to larger and more flexural deformation of the beam.

In addition, despite all specimens having different fibre volume fraction and same $l_{n} / d$ of 2.0 also show a similar flexural cracking-resistance load of $30 \mathrm{kN}$ and obvious 45-degree diagonal cracks finally, fibre volume fraction presents a significant influence on the cracking development of these beams. When the volume fraction increases up to $1.5 \%$, the two X-type cracks located at two ends of beams moved to the middle section of the beams until a new obvious X-type diagonal crack appeared at this zones. Besides, the distribution of all cracks in these beams is more uniform shown as Fig.11. In other word, as fibre volume fractions increase, the ultimate failure modes of SFRC coupling beams were changed from shear-tension to shear compression or flexure-shear failure. 
This changing is very benefit to the shear resistance capacity and deformation of RC coupling beam under reversal cyclic shear loads.

Table.1 lists the main experimental parameters and results of all tested SFRC coupling beams, including failure mode and maximum shear resistance force etc., while Fig.11 demonstrates the ultimate damage situations of the specimens. The results show that $l_{n} / d$ ratio and steel fibre volume fraction both have a significant influence on the ultimate failure modes of the SFRC coupling beams. When the $l_{n} / d$ ratio of coupling beam exceeds 2.0 or fibre volume fraction reaches $2.5 \%$ of concrete, SFRC coupling beams usually failed with a flexure-dominant failure mode.

\subsubsection{General seismic response of SFRC coupling beams}

The hysteretic curve is an important result to check the seismic behaviour of RC elements and usually reflects some main points such as ultimate resistance capacity, stiffness and ductility development, as well as energy dissipation capacity. To understand the overall seismic performance of the SFRC coupling beams, Fig.12 compares the hysteretic response of shear force-displacement of some representative specimens.

The results show that the SFRC coupling beams with a high $l_{n} / d$ ratio can exhibit larger ductility capacity owing to the beams have better flexural deformation capacity. Besides, the specimen with $l_{n} / d$ of 3.5 presents an excellent energy dissipation behaviour, stable stiffness degradation and large deformation capacity, as well as fails in a typical flexure failure mode. On the other hand, the results indicated that the compressive strength of fibre concrete has no significant effect on the initial stiffness of the SFRC coupling beams, while higher strength concrete can improve their ultimate shear strengths and corresponding ultimate deformation levels. This is explained by the fact: when fibre concrete compressive strengths are between $30 \mathrm{MPa}$ and $40 \mathrm{MPa}$, the contribution of steel fibre on the ductility property of coupling beams is very limited due to the bond action is small level between this straight type steel fibre and concrete. When fibre concrete compressive strength increases, the energy dissipation capacity of SFRC coupling beams was improved with a considerable degree. Therefore, the enhancing effectiveness of steel fibres on the whole deformation capacity and ultimate shear resistance of SFRC coupling beams depends significantly on concrete compressive strength. Additionally, normal RC coupling beam shows a typical pinched force-displacement response characteristic when compared to SFRC coupling beams and usually fails with shear failure mode. This indicates the addition of steel fibre increases the energy dissipation and deformation capacity of $\mathrm{RC}$ coupling beams. This kind pinched hysteretic response was improved significantly when steel fibre volume fraction increases, especially as the fraction is higher than $2.0 \%$. Furthermore, tensile reinforcements also trend to reach their yielding strengths when more steel fibres are used in concrete, which means these SFRC coupling beams can resist a larger lateral deformation.

Fig. 13 shows the initial response of the envelope curves of force-displacement of all tested 
SFRC coupling beams. Experimental result also verifies that SFRC coupling beams have higher initial stiffness when low $l_{n} / d$ ratio was used, which is similar as normal RC coupling beam. When the fibre concrete compressive strengths increase up to $70 \mathrm{MPa}$, the higher concrete compressive strength has resulted in an increase in the initial stiffnesses of the beams. However, when fibre concrete compressive exceeds than 70MPa), because of the obvious brittle behaviour of concrete, the initial stiffnesses of SFRC coupling beams decrease as concrete compressive strength, as shown in Fig.13. As for the effect of steel fibre on the initial stiffness of coupling beams, the beams with steel fibre present a better initial deformation capacity comparing with the conventional ones.

\subsubsection{Effect of main variables on shear strength of SFRC coupling beams}

As described previously in Section 3, the major shear contributions of SFRC coupling beams usually come from three components, i.e. steel fibre reinforced concrete, shear (vertical) reinforcements and steel fibre in main cracked sections. Fig.14 and Table.1 show a clear description related to the effects of fibre concrete compressive strengths, fibre volume fractions and $l_{n} / d$ ratio of beam on the ultimate shear strengths of SFRC coupling beams failed in shear dominant failure mode. Results show that these three parameters all have a significant influence on the ultimate shear strength of SFRC coupling beams. The shear strength of SFRC coupling beams increases with steel fibre volume fraction and fibre concrete compressive strength, and decreases as the $l_{n} / d$ ratio of coupling beam.

\section{Verification of the proposed formula in this study}

In order to evaluate the accuracy and reasonability of existing models to predict the shear strength of SFRC coupling beams and to check the proposed calculation method (i.e. Equation (18)) in this study, Fig. 15 compares the strength ratios $\left(V_{\text {exp }} / V_{\text {model }}\right)$ between experimental shear strength $\left(V_{\text {exp }}\right)$ and their corresponding calculative values $\left(V_{\text {model }}\right)$ obtained by various models, using the experimental results of the present study and the collected test data from literature review which focused on SFRC coupling beams reinforced by conventional reinforcements [12]. According to the comparative results, the proposed model exhibits an improved-significantly prediction accuracy and high reasonability. The maximum and minimum values of the $V_{\text {exp }} / V_{\text {model }}$ ratios of this model are 1.28 and 0.97 , respectively, are better than that of the other two models. Besides, the detailed statistical results of the ratios of $V_{\text {exp }} / V_{\text {model }}$ of the proposed model also indicate that it provides the closest agreement with the existing experimental results, with a mean ratio of 1.08 , a standard deviation of 0.09 and a coefficient of variation of $8.28 \%$.

Furthermore, aiming to further examine the reliability of the proposed model to estimate the shear strength of SFRC coupling beams in future practical design work, Fig.16 studies the relationship between $V_{\text {exp }} / V_{\text {model }}$ ratios and several main structural factors of coupling beams, such as concrete compressive strength, fibre volume fraction and span-to-depth ratio of beam $l_{n} / d$. As 
presented in the figure, no obvious tendency is observed for the concrete compressive strength and fibre volume fraction. This indicates that the current proposal can be used to design SFRC coupling beams when using different concrete compressive strength or fibre volume fraction in practical engineering. For shear span ratio $l_{n} / d$, however, when it is less than 2.0 , the negative effect of increasing $l_{n} / d$ ratio on the shear resistance of SFRC coupling beams should be concerned carefully in design work. In theory, as shown in Fig.14, it is a normal and expected reaction for RC elements for their stiffnesses increase as their $l_{n} / d$ ratios. Harries et al. [31] has reported some similar findings as regard to the effect of $l_{n} / d$ ratio on the concrete shear contribution of diagonally RC coupling beams. Besides, the experimental observations plotted in Figs.12-14 in the present study also verify that the $l_{n} / d$ ratio has a significant effect on the ultimate shear strength and stiffness of SFRC coupling beams.

Though the proposed shear model evaluates the shear strength of SFRC coupling beams subjected to seismic load well, it should take into account further the effect of $l_{n} / d$ to obtain a more accurate and reasonable prediction results. Therefore, a new model for predicting the shear strength of SFRC coupling beams are acquired, which shown as,

$V_{S F C B}=\eta V_{C B}=\left[1.46-0.21\left(l_{n} / d\right)\right] V_{C B}$

The comparison and statistical analysis results between predicted shear strengths based on the new shear model and experimental values are expressed in Fig.17. The results show that the proposed model presents the highest accuracy and reliability comparing to other models mentioned above, with a mean of 0.99 , a standard deviation of 0.05 and a coefficient of variation of $4.69 \%$.

\section{Conclusions}

In this paper, based on a theory analysis on shear transfer mechanism of the diagonal cracked section of SFRC coupling beams, a new strength model was developed to predict the shear strength of SFRC coupling beams with a span-to-depth ratio $\left(l_{n} / d\right)$ of less than 2.0 and reinforced by conventional reinforcements. The model used the Mohr-Coulomb failure criterion to evaluate the shear stress provided by steel fibre concrete located at main diagonal cracked section, as well as considered the negative effect of $l_{n} / d$ ratio on the shear resistance behaviour of SFRC coupling beam. To examine and improve the accuracy and reliability of the proposed model, the seismic behaviour of 17 SFRC coupling beams has been investigated experimentally in this study. In summary, the following conclusions can be drawn:

(1) Taking into account the positive effect of steel fibre on concrete, the Mohr-Coulomb failure criterion used in fibre reinforced concrete was expressed as a simplified function of shear and normal stress with an enhancing factor involving steel fibre volume fraction.

(2) Fibre volume fraction and span-to-depth $\left(l_{n} / d\right)$ ratio both have a significant influence on 
the ultimate failure modes of SFRC coupling beams subjected to seismic loads. When the $l_{n} / d$ ratio is greater than 2.5 or fibre volume fraction is higher than $2.5 \%$, SFRC coupling beams usually fail with a flexure-dominant failure mode, which avoids effectively a brittle shear failure.

(3) Span-to-depth ratio has a significant influence on the deformation and shear resistance of SFRC coupling beams subjected to seismic loads. As the ratio increases, the coupling beams presented larger initial deformation stiffness, higher energy dissipation and more stable stiffness degradation post-peak. The experimental results also indicated that the shear resistance capacity of SFRC coupling beams reduces with their $l_{n} / d$ ratios.

(4) The enhancing effectiveness of steel fibres on the deformation and shear resistance of RC coupling beams depends significantly on fibre concrete compressive strength for avoiding the early crushing damage of concrete.

(5) Using the Mohr-Coulomb failure criterion and considering major structural parameter on the shear resistance of coupling beams, this paper proposed a simplified model for predicting the shear strength of SFRC coupling beams. The existing and proposed models have been examined and compared using the present study and previous available test data. The comparative result showed that the proposed model evaluates the shear strength of SFRC coupling beams with $l_{n} / d$ ratio of less than 2.0 well, with the highest accuracy and reliability comparing with others.

\section{Acknowledgments}

The study presented in this paper was supported by the National Natural Science Foundation of China under grant No. 51078333 awarded to Zhengzhou University, China. In addition, the authors specially thank to Mr. Xin Ma, Bo Jia and Bin Li for their helps in experimental tests.

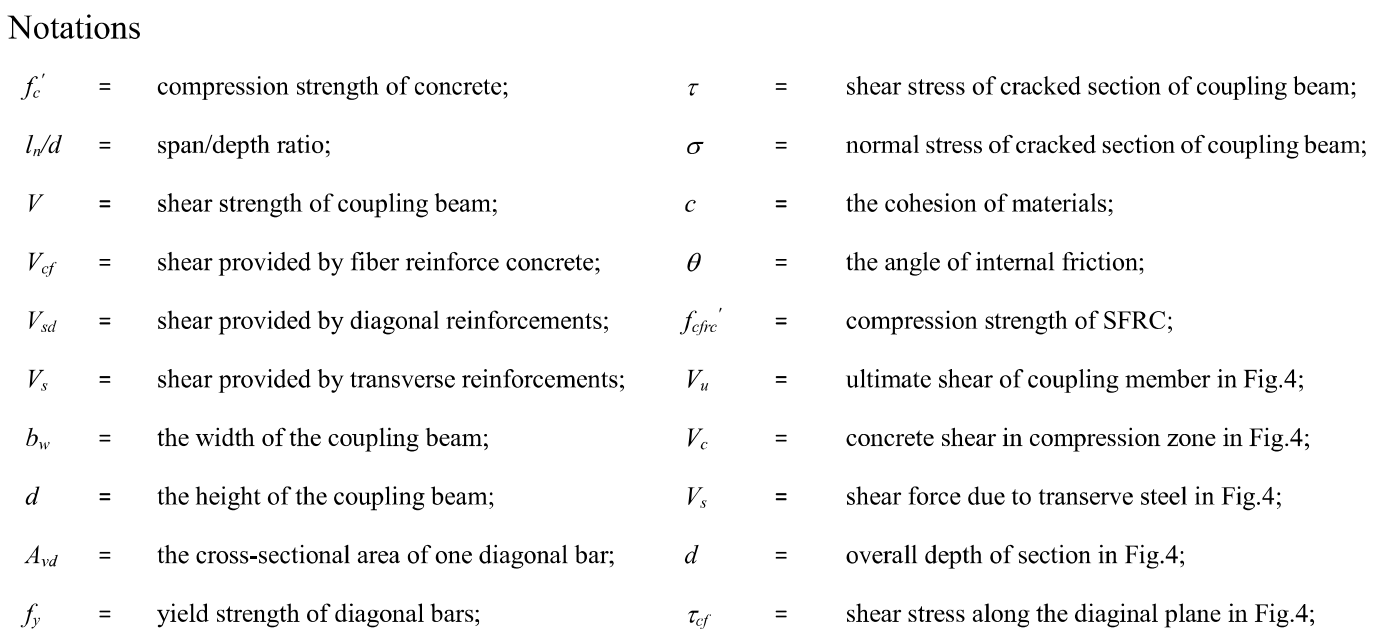




\begin{tabular}{|c|c|c|c|c|c|}
\hline$f_{y t}$ & $=$ & yield strength of transverse reinforcements; & $\sigma_{c f}$ & $=$ & normal stress perpebdicular direction in Fig.4; \\
\hline$A_{v}$ & $=$ & the cross-sectional area of shear rebars; & $T$ & $=$ & tension of longitudinal steel in Fig.4; \\
\hline$S$ & $=$ & spacing of transverse reinfrocements; & $F c$ & $=$ & concrete force in compression zone; \\
\hline$f_{t}$ & $=$ & tensile strength of original concrete; & $A, B$ & $=$ & calculation factors; \\
\hline$\lambda_{f}$ & $=$ & factors of steel fiber, calculated as $\rho_{f} l_{f} / d_{f}$; & $\gamma$ & $=$ & compression-to-tension strengths ratio; \\
\hline$\rho_{f}$ & $=$ & volume fraction of steel fiber; & $V_{C B}$ & $=$ & proposed shear strength of coupling beam; \\
\hline$l_{f} / d_{f}$ & $=$ & aspect ratio of steel fiber; & $\eta$ & $=$ & affecting factor due to $1_{\mathrm{n}} / \mathrm{d}$; \\
\hline$h_{0}$ & $=$ & effective height of coupling beam; & $V_{S F C B}$ & $=$ & modified shear strength for SFRC coupling \\
\hline
\end{tabular}

\section{References}

[1]. Canbolat, B. A., Parra-Montesinos, G. J., Wight, J. K. (2005). Experimental study on seismic behavior of high-performance fibre-reinforced cement composite coupling beams. $A C I$ Structural Journal, 102(1).

[2]. Paulay T., Priestley M.J.N. (1992) Seismic design of reinforced concrete and masonry buildings, John Wiley \& Sons, INC. pp744.

[3]. Luisoni, C. J.; Somenson, H. M.; and Ungaro, M. A., (1970) Verificación Experimental de un CálculoPlástico y OtroElástico do unaPatred de Corte, IV SimposioPanamericano de Estructuras, V. 5, pp. 230-286. [In Spanish]

[4]. Paulay, T., Binney, J. R. (1974). Diagonally Reinforced Coupling Beams of Shear Walls, Shear in Reinforced Concrete, SP-42, V. 2, American Concrete Institute, Farmington Hills, Mich., pp. 579-598.

[5]. Paulay, T., Santhakumar, A. R. (1976). Ductile Behavior of Coupled Shear Walls, Journal of the Structural Division, ASCE, V. 102, pp. 93-108.

[6]. American Iron and Steel Institute, 1975, Earthquakes, pp. 160-161.

[7]. Shiu, N. K.; Barney, G. B.; Fiorato, A. E.; and Corley W. G. (1978). Revering Load Tests of Reinforced Concrete Coupling Beams, Proceedings of the Central American Conference on Earthquake Engineering, El Salvador, pp. 239-249.

[8]. Chaallal, O., Thibodeau, S., Lescelleur, J., \&Malenfant, P. (1996). Steel fibre or conventional reinforcement for concrete shearwalls. Concrete International, 18(6), 39-42.

[9]. Spadea, G. and Bencardino, F. (1997). Behavior of Fibre-Reinforced Concrete Beams under Cyclic Loading. J. Struct. Eng., 123(5), 660-668.

[10]. Lequesne, R. D., Parra-Montesinos, G. J., \& Wight, J. K. (2012). Seismic Behavior and Detailing of High-Performance Fibre-Reinforced Concrete Coupling Beams and Coupled Wall Systems. Journal of Structural Engineering, 139(8), 1362-1370.

[11]. Parra-Montesinos, G. J. (2005). High-performance fibre-reinforced cement composites: 
an alternative for seismic design of structures. ACI Structural Journal, 102(5), 668.

[12]. Zhang, HZ., Zhang RJ., Huang CK. Experimental study of shear resistance of steel fibre reinforced high strength concrete coupling beams, China civil engineering journal, 40(11),15-22. [In Chinese]

[13]. Aktan, A.E., \& Bertero, V.V. (1981). The seismic resistant design of R/C coupled structural walls. NASA STI/recon technical report n, 82, 17417.

[14]. Aristizabal-Ochoa, J.D. (1987). Tapered beam and column elements in unbraced frame structures. Journal of computing in civil engineering, 1(1), 35-49.

[15]. ACI 318-11. (2011). Building Code Requirements for Structural Concrete (ACI 318-11) and Commentary. Farmington Hills.

[16]. Lequesne, R.D. (2011). Behavior and design of high-performance fibre-reinforced concrete coupling beams and coupled-wall systems (Doctoral dissertation, The University of Michigan).

[17]. GB50010-2002. (2002). Code for design of concrete structures, English version. National standard of China, China architecture and building press, Beijing.

[18]. Gong BN., Fang EH. (1988). Behavior of reinforced concrete coupling beams between shear wall under cyclic loading. Chinese Journal of Building structures, 9(1), 34-41.[In Chinese] [19]. Juvinal, Robert C. Marshek, Kurt. (1991). Fundamentals of machine component design.2nd ed., 1991, pp. 217, ISBN 0-471-62281-8

[20]. Khalifa, E. S. (2014). Analytical model for steel fibre concrete composite short-coupling beam. Composites Part B: Engineering, 56, 318-329.

[21]. Cai, G., Sun, Y.P, Takeuchi, T., Zhang, J. (2015). Proposal of a complete seismic shear strength model for circular concrete columns. Engineering Structures, 100, 399-409.

[22]. Paulay T., Priestley M.J.N. Improved analytical model for shear strength of circular reinforced concrete columns in seismic regions, ACI Structural Journal 97 (3) (2000) 388-396.

[23]. ASCE-ACI Task Committee 426. (1973). The Shear Strength of Reinforced Concrete Members, ASCE Journal of Structural Div., Vol. 99, pp. 1091-1187.

[24]. Priestley, M. N., Verma, R., Xiao, Y. (1994). Seismic shear strength of reinforced concrete columns. Journal of structural engineering, 120(8), 2310-2329.

[25]. Architecture institute Japan. (2010). AIJ standard for structural calculation of steel reinforced concrete structures. Marauzen, Tokyo. [In Japanese]

[26]. Xu, B.W., Shi, H.S. (2009). Correlations among mechanical properties of steel fibre reinforced concrete. Construction and Building Materials, 23(12), 3468-3474.

[27]. Zollo, R.F. (1997). Fibre-reinforced concrete: an overview after 30 years of development. Cement and Concrete Composites, 19(2), 107-122.

[28]. CECS13-2009. (2010). Standard test methods for fibre reinforced concrete, Chinese 
association for engineering construction standardization, China Planing press, Beijing.

[29]. JGJ101-1996. (1997). Specification of test methods for earthquake resistant building, China industry standards, Beijing.

[30]. Tassios, T. P., Moretti, M., Bezas, A. (1996). On the behavior and ductility of reinforced concrete coupling beams of shear walls. ACI Structural Journal, 93(6).

[31]. Harries, K. A., Fortney, P. J., Shahrooz, B. M., Brienen, P. J. (2005). Practical design of diagonally reinforced concrete coupling beams-critical review of ACI 318 requirements. $A C I$ Structural Journal, 102(6). 


\section{Table and figure list}

Table.1Details of the specimens and main results

Fig.1 RC wall, coupling beams and their seismic design

Fig.2 Some examples of reinforcement arrangements in RC coupling beams

Fig.3 Mohr-Coulomb failure criterion envelope curve

Fig.4 Shear transfer mechanism of SFRC coupling beams

Fig.5 Compression and splitting tensile strength of steel fibre reinforced concrete

Fig.6 Determination of factors in shear calculation in SFRC coupling beam

Fig.7 Enhancing coefficient of steel fibre vs. fibre volume fraction in SFRC

Fig. 8 Details of SFRC coupling beams

Fig.9 Test setup

Fig.10 Applied loading protocol

Fig.11 Ultimate failure situation of SFRC coupling beams

Fig.12 Lateral force vs. displacement of some representative SFRC specimens

Fig.13 Initial response of envelope curve of lateral force vs. displacement

Fig.14 Test variables vs. shear strengths of SFRC coupling beams

Fig.15 Comparison of predicted strength ratio based on existing and proposed models

Fig. 16 Effect of variables on the predicated strength ratio based on proposed model

Fig. 17 Comparison between experimental results and proposed model 


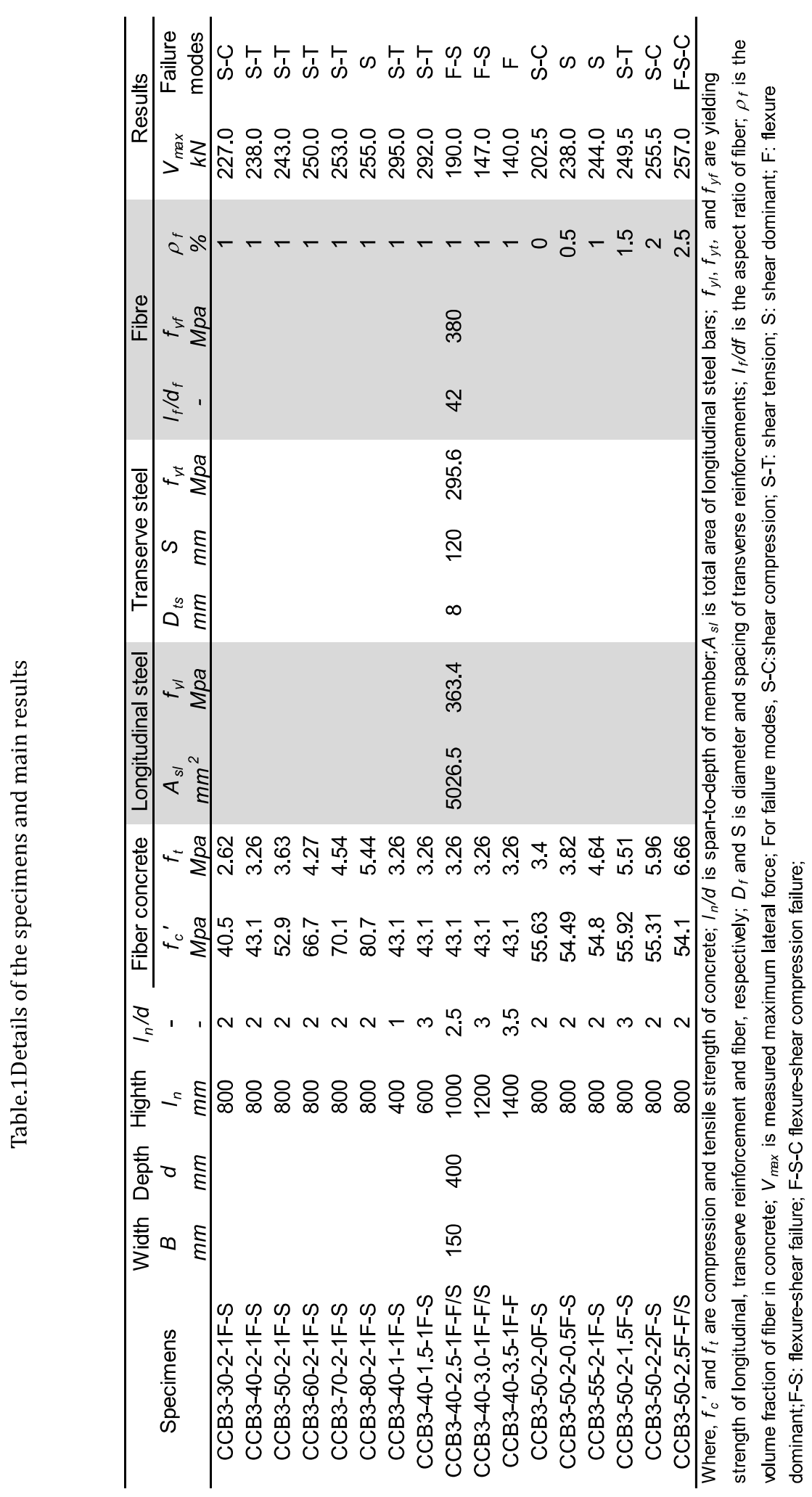




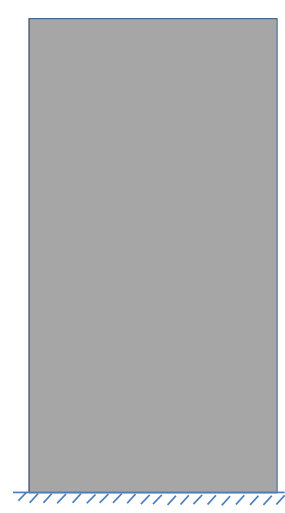

(a) Single RC wall

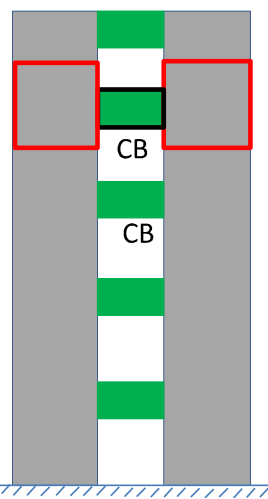

(b) Coupled RC wall by CBs

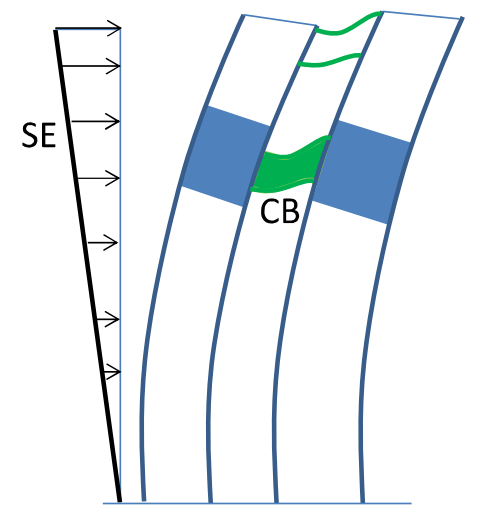

(c) Seismic effects and deformation

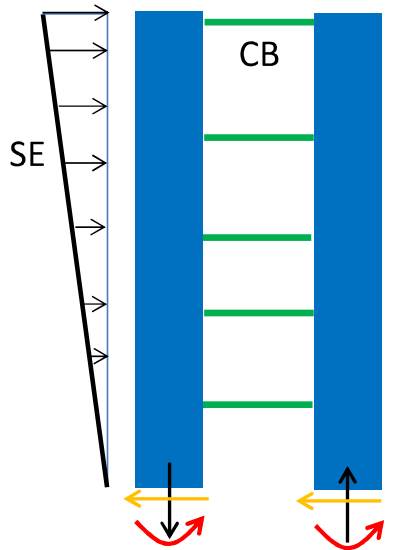

(d) Calculation mode (whole)
CB: coupling beam $G$ : gravity SE: seismic effects

Fig.1 RC wall, coupling beam and their seismic design

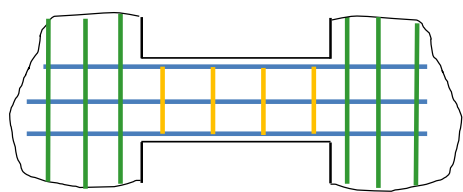

(a) Conventional

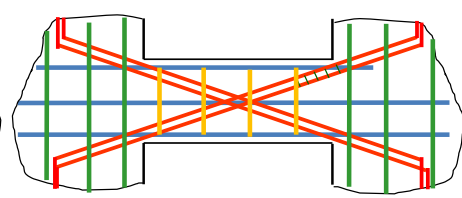

(b) Diagonal

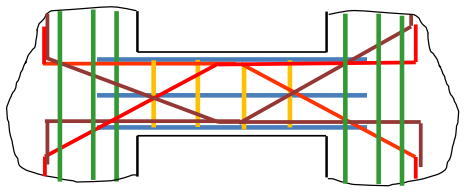

(c) Crossover

Fig.2 Several arrangement examples of reinforcements in RC coupling beams 

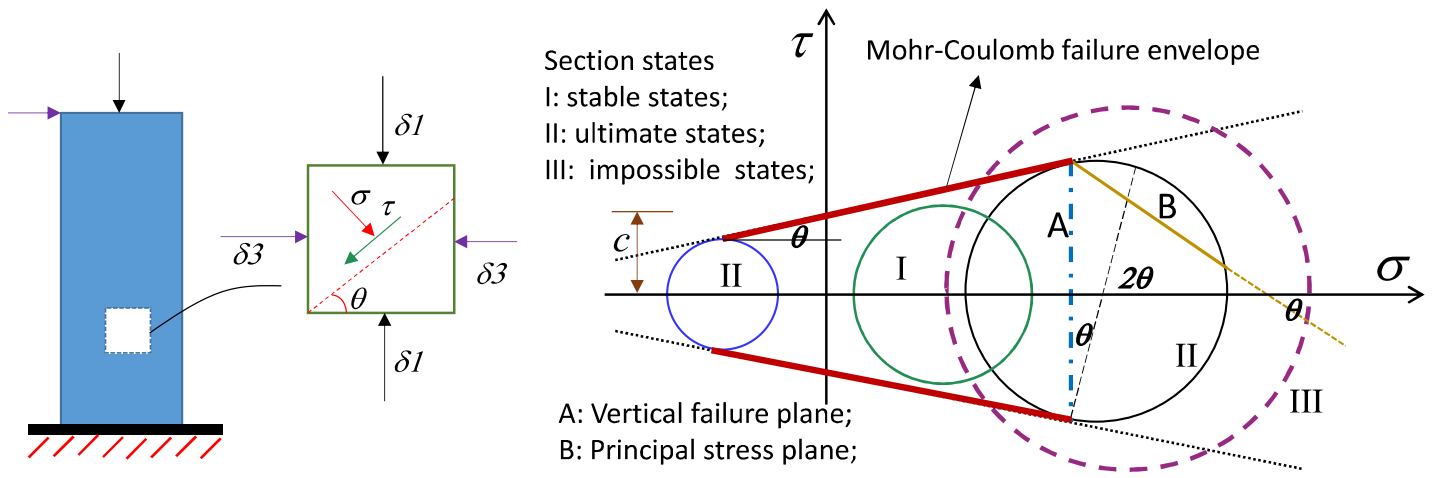

Fig.3 Mohr-Coulomb failure criterion envelope curve

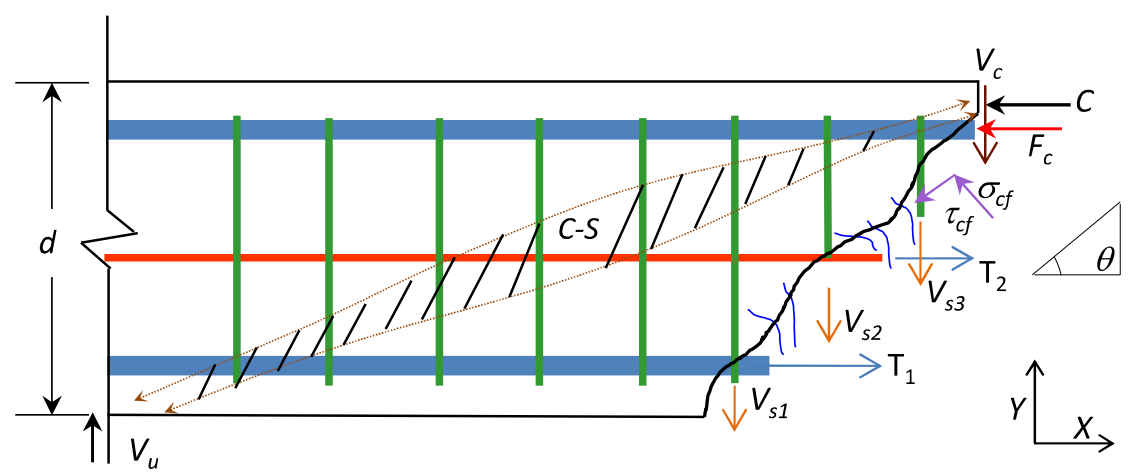

$F_{c}$ : Concrete compression; $\quad V_{c}$ : Concrete shear in compression zone;

$T$ : Tension of longitudinal steel; $\quad V_{s}$ : Shear force due to transverse steel;

$\tau_{c f}$ : Shear stress along the diagonal plane; $V_{u}$ : Ultimate shear of member;

$\sigma_{c f}$ : Normal stress perpendicular direction; C-S: Internal compression strut effect;

$\theta$ : Degree of main diagonal crack; $\quad d$ : Overall depth of section;

Fig.4 Shear transfer mechanism of SFRC coupling beams
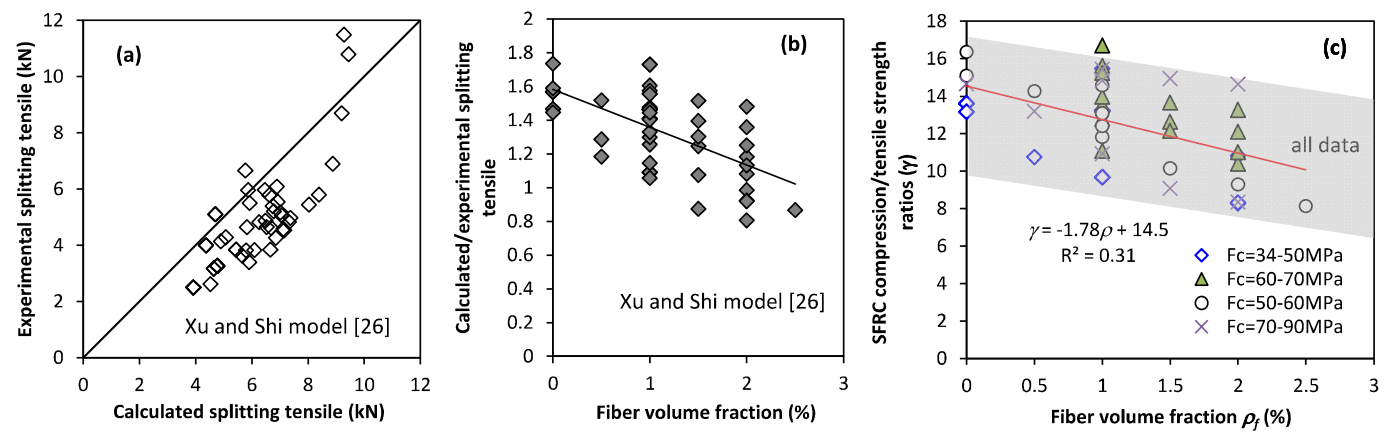

Fig.5 Compressive and splitting tensile strengths of steel fibre reinforced concrete 

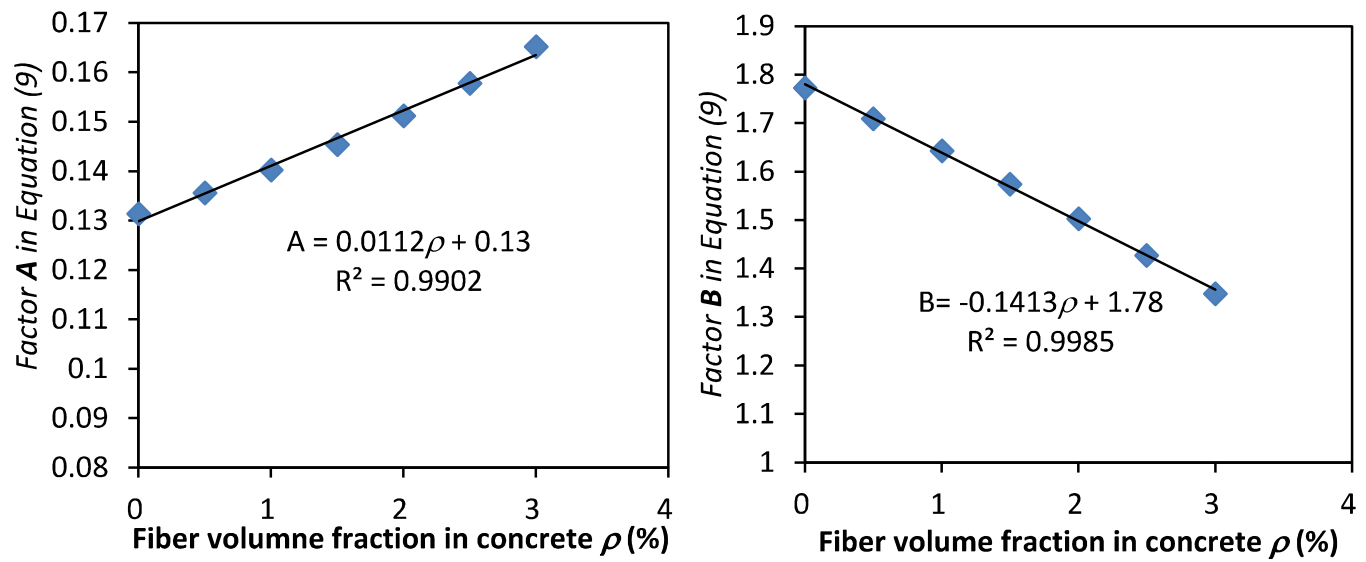

Fig.6 Determination of factors in shear calculation in SFRC coupling beam

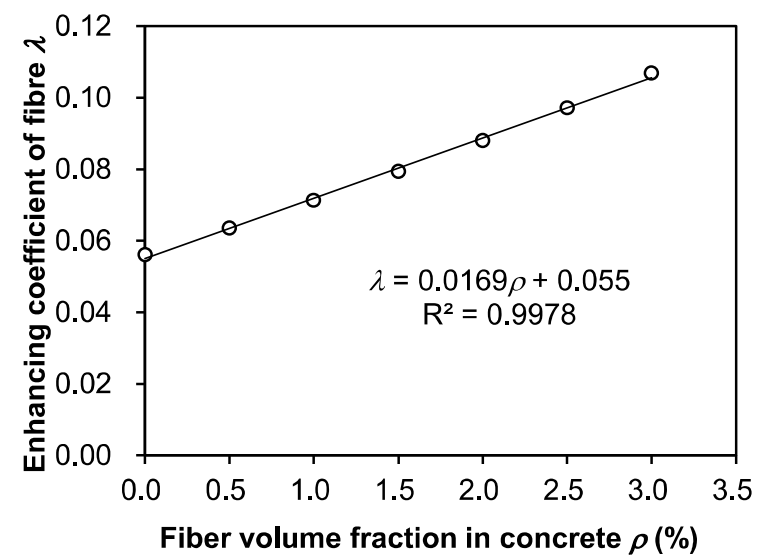

Fig.7 Enhancing coefficient of steel fibre vs. fibre volume fraction in SFRC

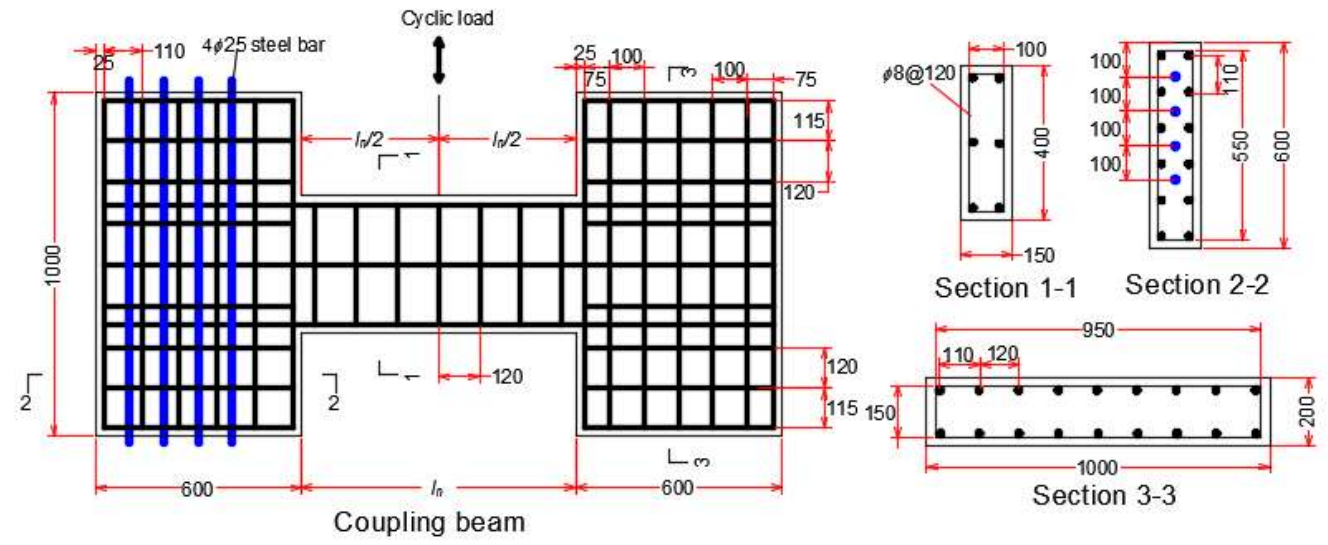

Fig.8 Details of SFRC coupling beams 

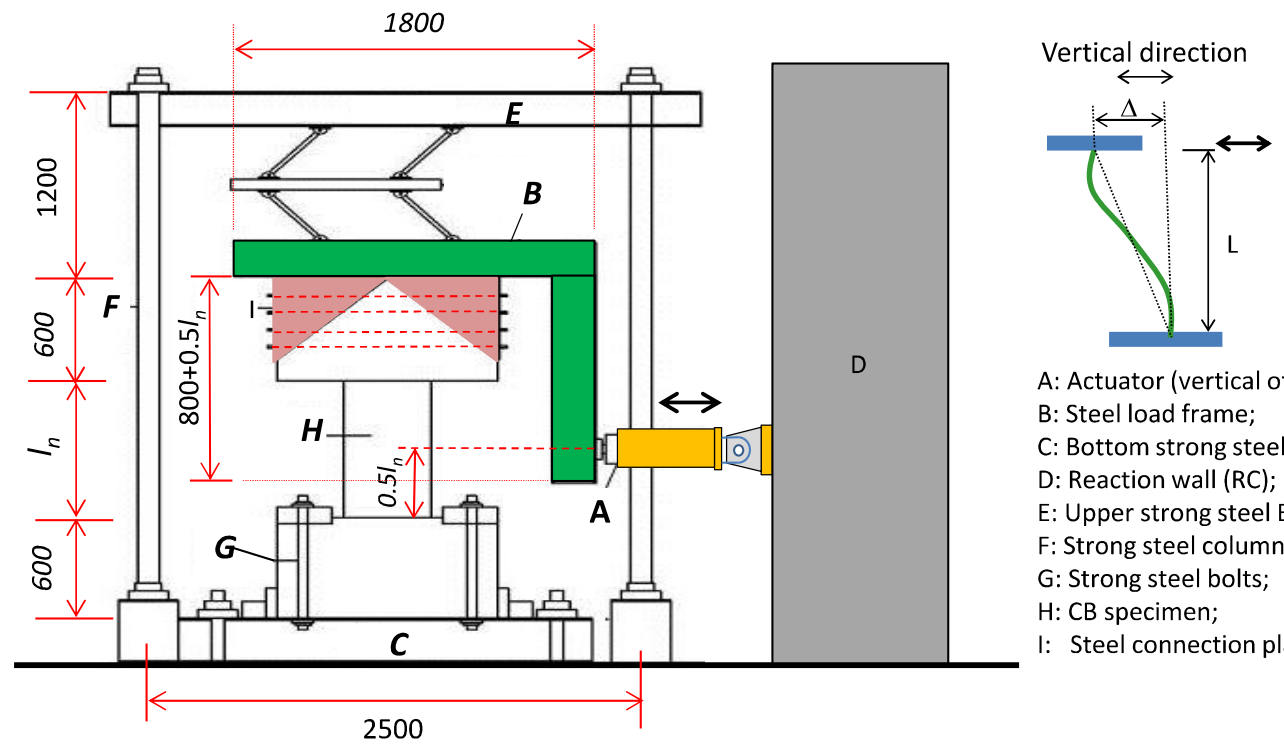

A: Actuator (vertical of CBs)

B: Steel load frame;

C: Bottom strong steel beam;

D: Reaction wall ( $\mathrm{RC}$ );

E: Upper strong steel Beam;

F: Strong steel columns;

G: Strong steel bolts;

$\mathrm{H}$ : CB specimen;

I: Steel connection plates;

Fig.9 Test setup

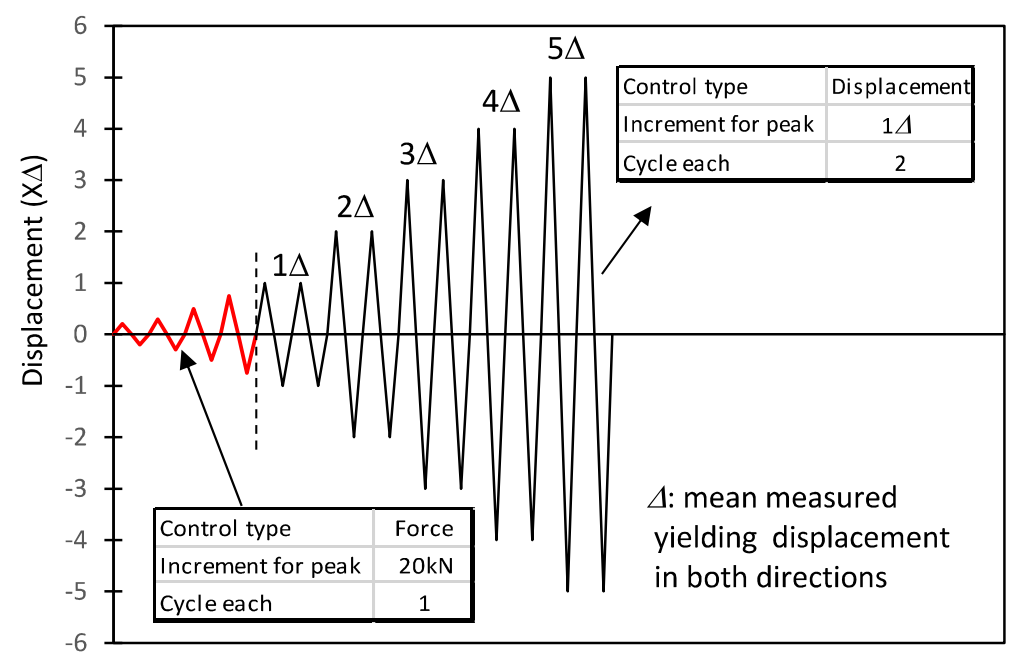

Fig.10 Applied loading protocol 



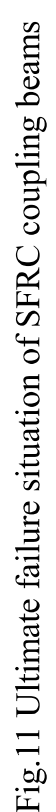
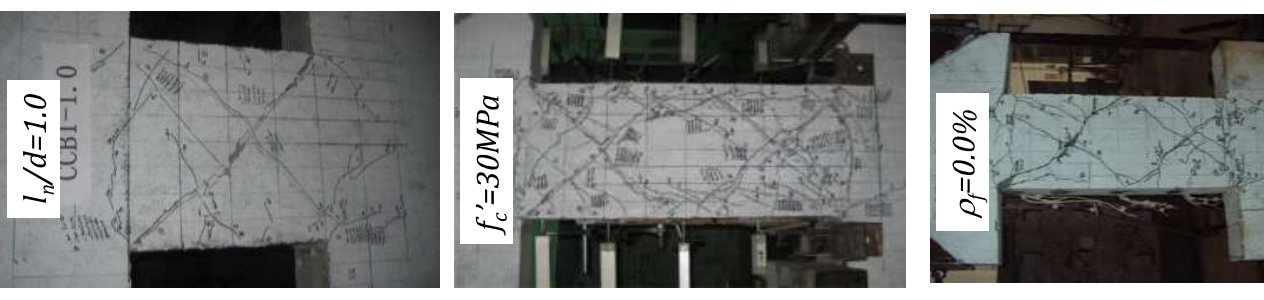


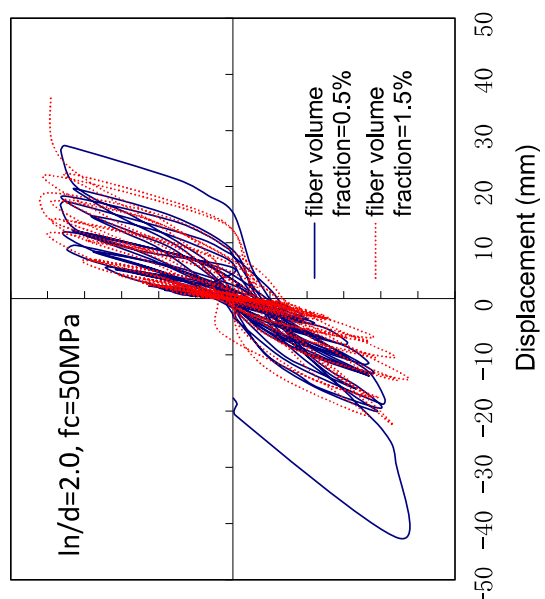

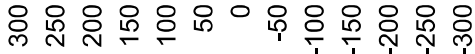

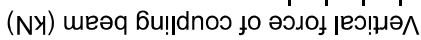

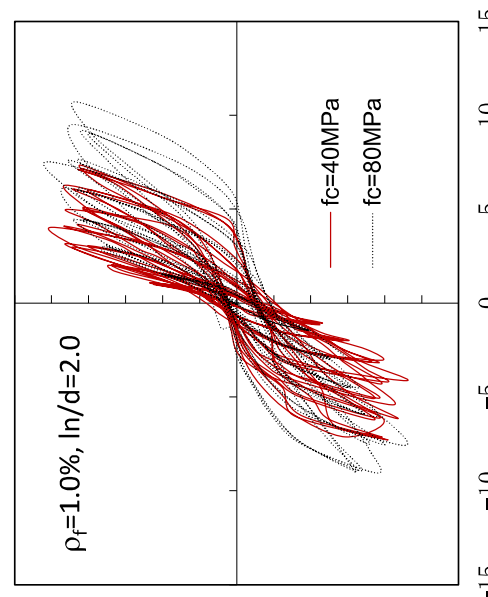

$\stackrel{20}{-1}$

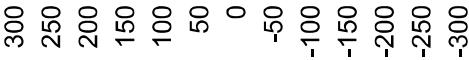

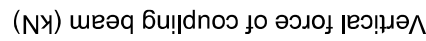

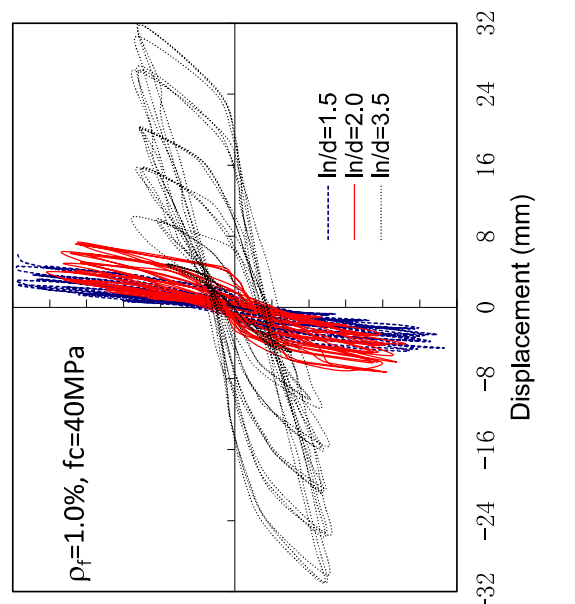

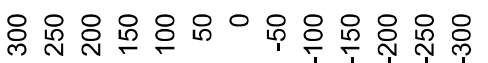

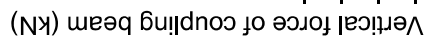




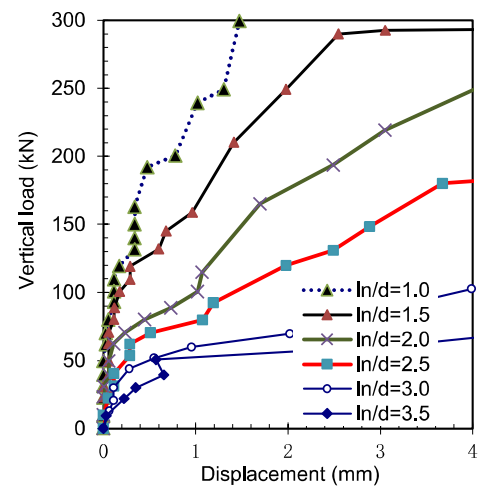

(a) Concrete 40MPa, $\rho_{\mathrm{f}}=1 \%$

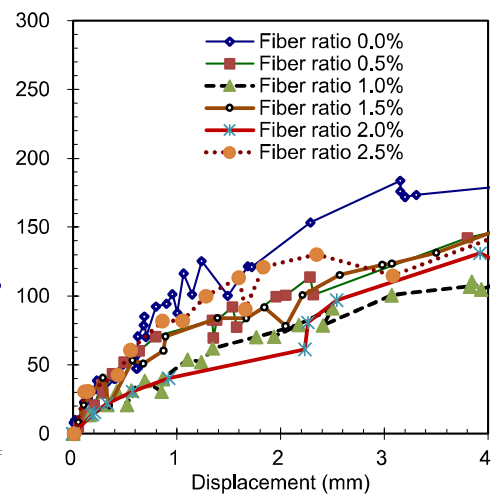

(b) Concrete $50 \mathrm{MPa}, \ln / \mathrm{d}=2.0$

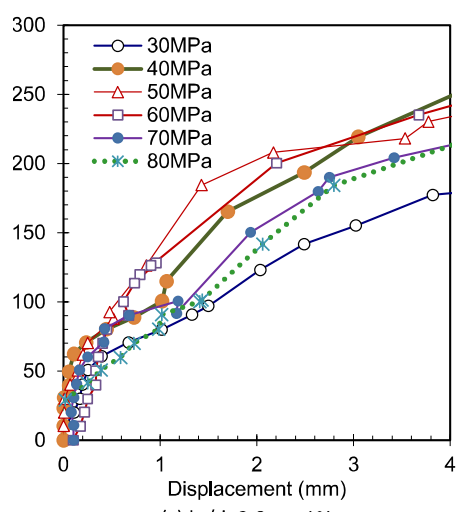

(c) $\ln / d=2.0, \rho_{\mathrm{f}}=1 \%$

Fig.13 Initial response of envelope curve of vertical force vs. displacement
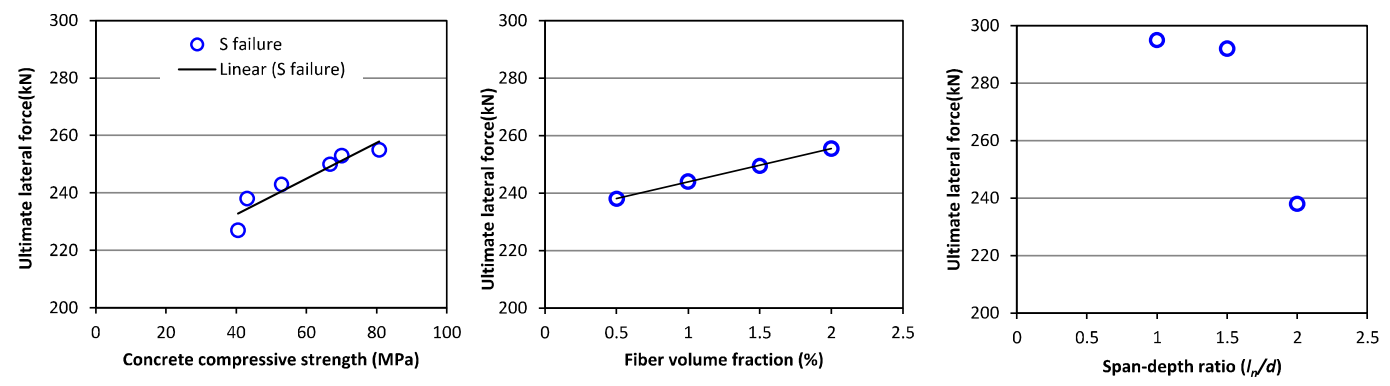

Fig.14 Tested variables vs. shear strengths of SFRC coupling beams
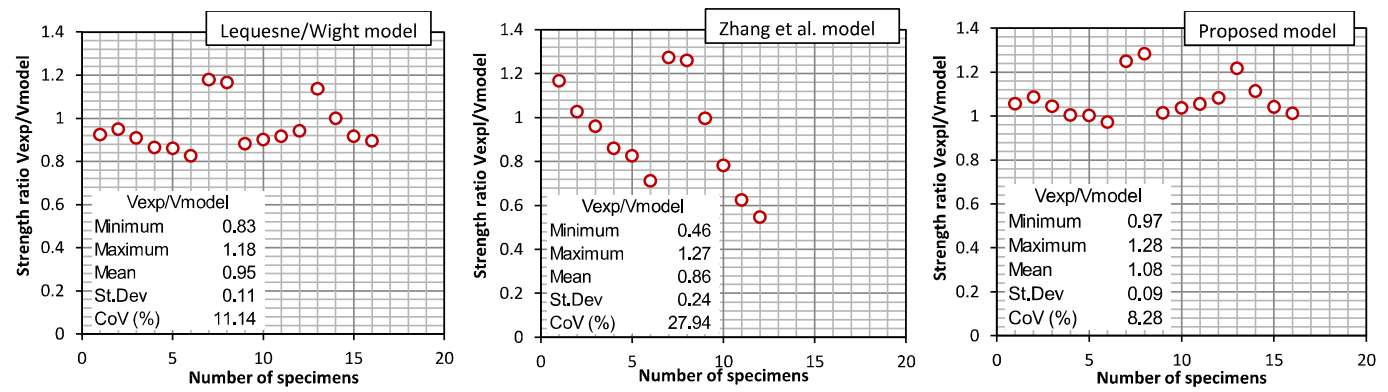

Fig.15 Comparison of predicted strength ratio based on existing and proposed models 

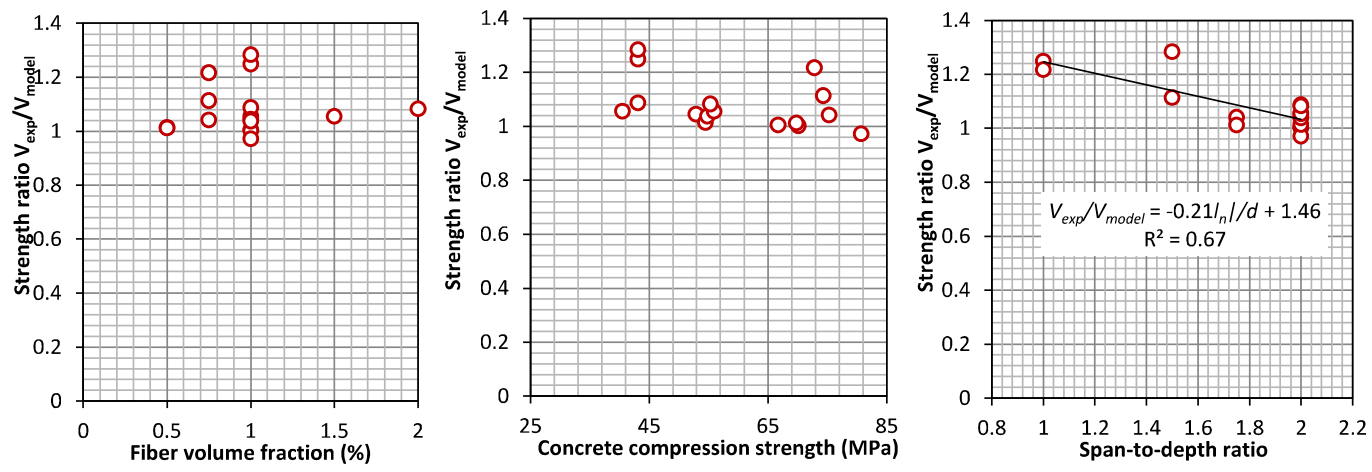

Fig.16 Effect of variables on the predicated strength ratio based on proposed model

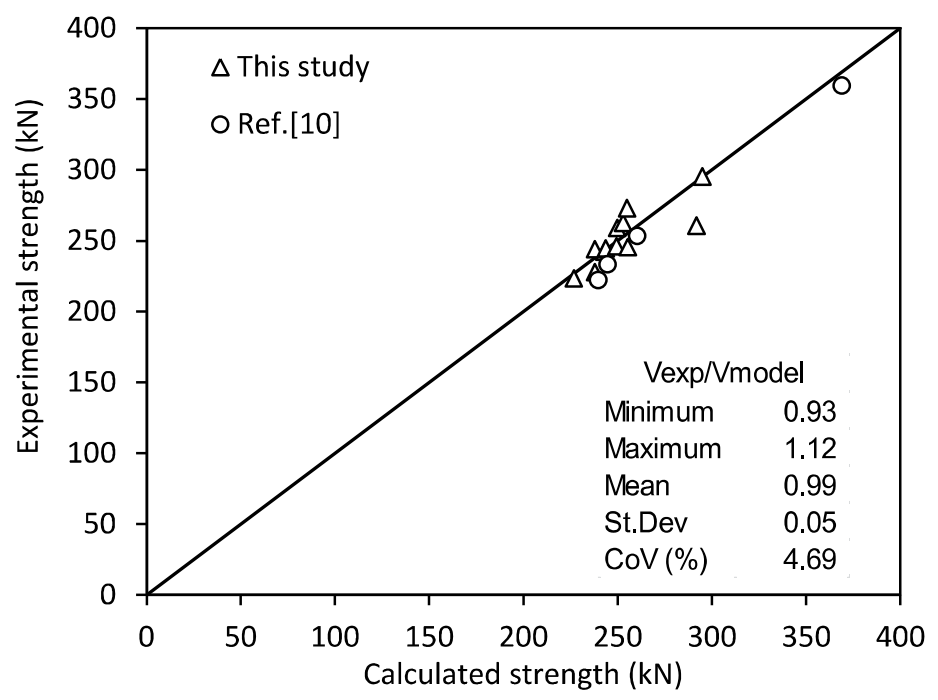

Fig.17 Comparison between experimental results and proposed model 